\title{
The effects of hypoxaemia in fetal sheep
}

\author{
J. S, ROBINSON, C. T. JONES, AND G. D. THORBURN
}

From the Nuffield Institute for Medical Research, Headley Way, Headington, and the Nuffield Department for Obstetrics and Gynaecology, Oxford

Fetal hypoxaemia may result from altered maternal $\mathrm{PaO}_{2}$ or a reduction in maternal placental or umbilical blood flow. It is also possible that reduction of gas exchange across the placenta could limit the oxygen supply to the fetus. In this review we will be concerned with the effects of hypoxaemia in fetal sheep during the latter half of pregnancy.

At present it is not easy to reduce maternal placental blood flow experimentally in a controlled manner, while an acute restriction of umbilical blood flow results in asphyxia (Towell and Salvador, 1974). Fetal hypoxaemia can be induced reproducibly by lowering maternal inspired oxygen concentrations and hence $\mathrm{PaO}_{2}$. During such experiments, the fetal blood gas tensions take several minutes to equilibrate while the cardiovascular and plasma changes require up to $60 \mathrm{~min}$ to reach a relatively steady state (Boddy et al, 1974a; Cohn et al, 1974; Jones and Robinson, 1975; Rurak, 1976a and b; Jones, 1977). Although the acute episodes of hypoxaemia known to occur spontaneously last only a few minutes (Jones and Ritchie, 1976; Patrick et al, 1976), studying changes over a 60 -min period provides more detailed information.

A different approach has been used to produce long-term hypoxaemia in the fetus so as to minimize the effects on the mother. This has been either to reduce placental mass surgically (Alexander, 1964), to embolize the maternal placenta with microspheres (Creasy et al, 1972), or to reduce umbilical blood flow by umbilical artery ligation (Emmanouilides $e t$ al, 1968).

It is important when investigating fetal hypoxaemia to avoid the effects of anaesthesia and surgery. Such acute experiments are associated with much higher hormone (at least 10 fold higher for ACTH, catecholamines and vasopressin) and metabolite concentrations than in chronically catheterized fetal preparations. For instance, the plasma catecholamine concentration in the exteriorized fetal sheep is higher than that normally seen during hypoxaemia in fetal sheep in utero (Jones and Robinson, 1975; Jones and Rurak, 1976a) and hypoxaemia causes a tachycardia in the exteriorized fetus compared with an initial bradycardia in utero. We will therefore concentrate on the cardiovascular, metabolic and endocrine changes observed with both short-term and chronic hypoxaemia in the conscious unrestrained sheep with implanted catheters.

\section{Short-term hypoxaemia}

\section{CARDIOVASCULAR CHANGES}

During experiments in which ewes were given 9 per

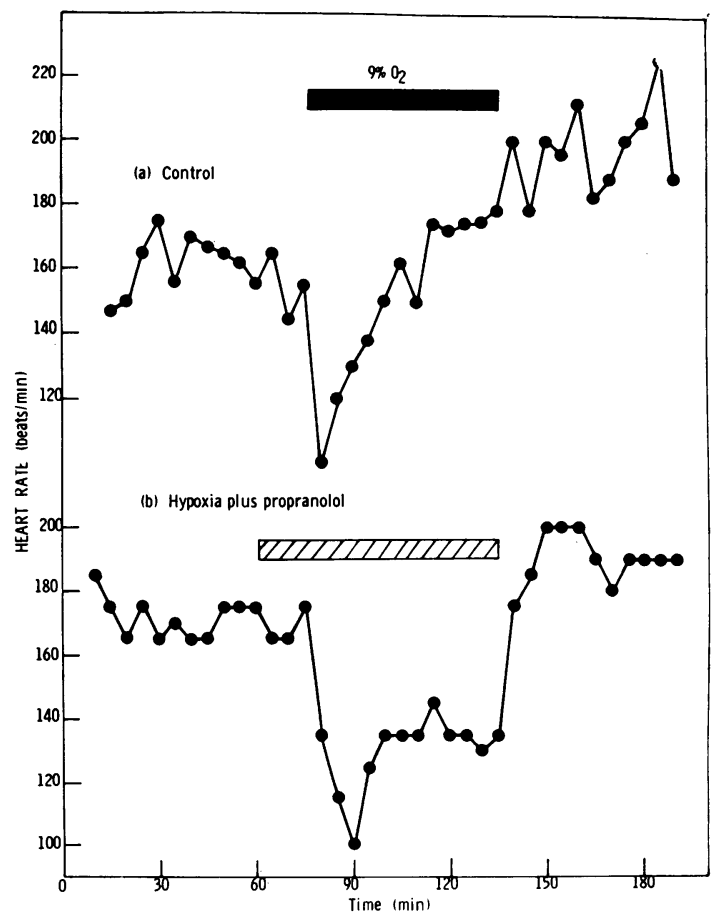

Fig 1 The effects of hypoxaemia (a) and hypoxaemia plus propranolol infusion (b) on the heart rate of fetal sheep of 125 days; ( hypoxaemia induced by causing ewes to breath 9 per cent $\mathrm{O}_{2}$ plus 3 per cent $\mathrm{CO}_{2}$; (سय) propranolol infused at $44 \mu \mathrm{g} / \mathrm{min}$ into a fetal jugular vein. 
cent oxygen and 3 per cent carbon dioxide in nitrogen to breathe for one hour, fetal carotid arterial $\mathrm{PaO}_{2}$ fell from about 25 to $16 \mathrm{~mm} \mathrm{Hg}$ while $\mathrm{PaCO}_{2}$ remained steady. In most instances a small (about 0.06 ) but significant fall of $\mathrm{pH}$ occurred (Boddy et al, 1974a). The cardiovascular changes observed with this degree of hypoxaemia varied with gestational age. The heart rate in young fetuses $(<102$ days, term $\sim 145$ days) increased by about 50 beats $\mathrm{min}^{-1}$ but there was no significant change in arterial pressure. The initial response in older fetuses ( $>119$ days), however, was a bradycardia, the heart rate falling by about 30 beats min $^{-1}$, and this was accompanied by a $5-10 \mathrm{~mm} \mathrm{Hg}$ increase in arterial pressure (Boddy et al, 1974a; Cohn et al, 1974; Jones and Robinson, 1975; Rurak, 1976a and b) (fig 1a). The rise of arterial pressure is mainly due to activation of aortic body chemoreceptors (Dawes et al, 1969) and causes a bradycardia as a result of stimulation of the baroreceptors (Shinebourne et al, 1972). Bilateral cervical vagotomy abolishes the rise in arterial pressure with hypoxaemia and the fetal heart rate increases as in the younger fetuses (Boddy et al, 1974a; Rurak, 1976b).

Although Boddy et al (1974a) noted that the fetal heart rate gradually increased during hypoxaemia, Jones and Robinson (1975) found that the bradycardia persisted in some fetuses. They measured plasma noradrenaline and adrenaline concentrations and reported that both increased during hypoxaemia. The bradycardia persisted in those fetuses in which the catecholamine concentration was $<3 \mathrm{ng} /$ $\mathrm{ml}$ whereas the heart rate increased when it was $>8$ $\mathrm{ng} / \mathrm{ml}$ suggesting that high plasma catecholamine concentrations overcame vagal inhibition of the heart. Ritchie (1975) found that infusion of adrenaline $(1 \cdot 3 \mu \mathrm{g} / \mathrm{min})$ in fetal sheep increased arterial pressure and the heart rate fell, then rose (fig 2 ).

This rise in heart rate was prevented by the $\beta$ blocker, propranolol. When propranolol was infused during hypoxaemia, at a rate known to block the effects of circulating catecholamines on the heart, increased arterial pressure and persistent bradycardia occurred which suggests persistence of vagal activity (Jones and Ritchie, unpublished) (fig 1b). This indicates some of the ways in which the fetal heart rate may be under adrenergic control and it must be borne in mind that as the catecholamine stores of the fetal heart are low (Friedman, 1972) its sensitivity to exogenous catecholamines will be high (Friedman et al, 1968).

The increase in arterial pressure has been attributed to aortic body activity but may also result from the release of antidiuretic hormone (ADH) during hypoxaemia. Rurak (1976a and b) demonstrated a rise of ADH with hypoxaemia which cor-

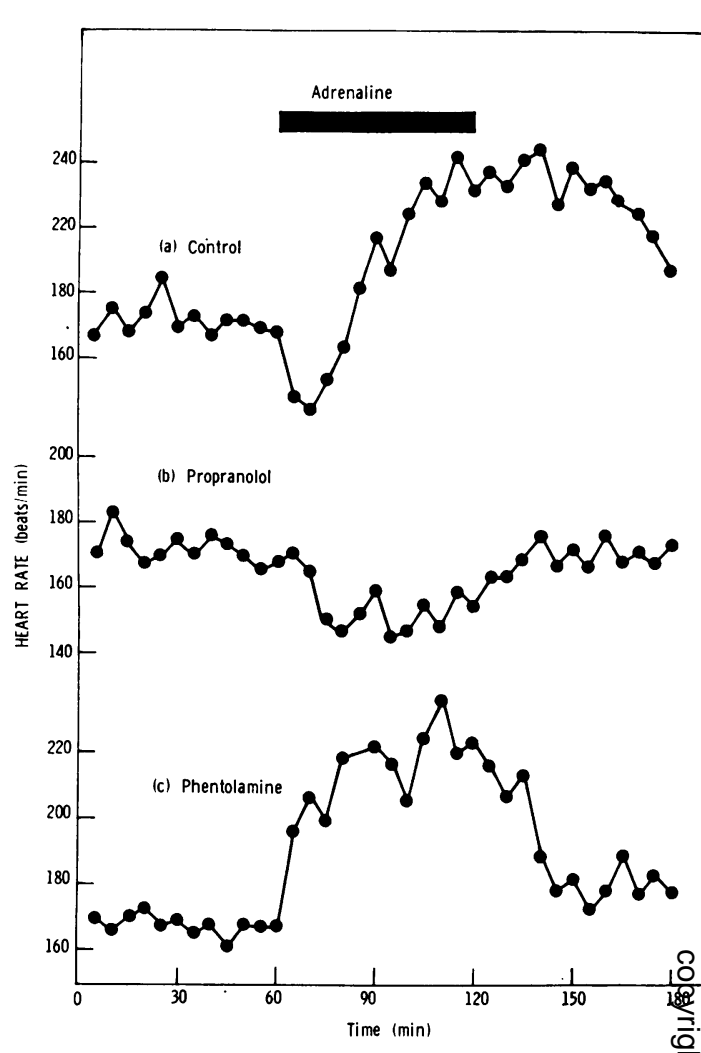

Fig 2 The changes in heart rate during the infusion of adrenaline into fetal sheep of 127 to 129 days; (a) adrenaline was infused into the fetal jugular vein at 1.3 $\mu \mathrm{g} / \mathrm{min}$; (b) propranolol was infused at $44 \mu \mathrm{g} / \mathrm{min}$ together with adrenaline; (c) phentolamine was infused at (100 $\mu \mathrm{g} / \mathrm{min})$ together with adrenaline; shows the period of adrenaline infusion.

related with the change in arterial pressure. $\mathrm{He}$ als $\overline{8}$. showed that fetal infusion of $\mathrm{ADH}$ to achieve simis lar plasma concentrations increased arterial press:ure. Vagotomy blunted but did not abolish the ADH release during hypoxaemia.

The acute experiments of Dawes and his colleagues (see Dawes, 1968) demonstrated redistribution of cardiac output during hypoxaemia with reduce blood flow to the lungs and hind limbs. This has beep re-examined in the chronic fetal sheep preparatio $\overline{\bar{H}}$ using radioactively labelled microspheres by Coh $\uparrow$ et al (1974). They separated the fetuses into two groups depending on the presence or absence of acidaemia during hypoxaemia. During hypoxaemia the proportion of cardiac output distributed to the placenta, heart, brain and adrenals increased, whereas the cardiac output and the flow to the gut, spleem kidneys and carcase decreased (table I). The greatest changes were observed in the group which developed acidaemia. 


\begin{tabular}{|c|c|c|c|c|}
\hline & Control & Hypoxaemia & Control & Hypoxuemia + Acidaemia \\
\hline Cardiac output $\left(\mathrm{ml} \mathrm{min} \mathbf{m}^{-1} \mathbf{k g}^{-1}\right)$ & 464 & 442 & 497 & $381^{*}$ \\
\hline $\begin{array}{l}\text { Umbilical blood flow (ml min-1 } \mathrm{kg}^{-1} \text { ) } \\
\text { Percentage distribution of cardiac output }\end{array}$ & 191 & 213 & 195 & 205 \\
\hline $\begin{array}{l}\text { to placenta } \\
\text { Organ blood flow }\left(\mathrm{ml} \min ^{-1} 100 \mathrm{~g}^{-1}\right)\end{array}$ & $41 \cdot 1$ & $47 \cdot 8 t$ & $41 \cdot 6$ & $56 \cdot 6^{*}$ \\
\hline \multicolumn{5}{|l|}{ Organ blood flow ( $\left.\mathrm{ml} \mathrm{min-1} 100 \mathrm{~g}^{-1}\right)$} \\
\hline $\begin{array}{l}\text { Gut } \\
\text { Spleen }\end{array}$ & $\begin{array}{r}67 \\
240\end{array}$ & $\begin{array}{l}53 \\
80+\end{array}$ & $\begin{array}{r}96 \\
352\end{array}$ & $\begin{array}{l}41 \dagger \\
50^{*}\end{array}$ \\
\hline Kidneys & 175 & $136^{*}$ & 162 & $81 \dagger$ \\
\hline Carcase & 20 & 14 & 20 & $6^{*}$ \\
\hline Lungs & 60 & 27 & 57 & $32 \dagger$ \\
\hline Heart & 179 & $449^{*}$ & 185 & $482 \dagger$ \\
\hline Brain & 96 & $168^{*}$ & 120 & $185^{*}$ \\
\hline Adrenals & 271 & $828^{*}$ & 302 & $855 \dagger$ \\
\hline
\end{tabular}

Table I Cardiac output and organ blood flow during hypoxaemia (Cohn et al, 1974) ${ }^{*} \mathrm{P}<0.01,+\mathrm{P}<0.05$.

Episodes of spontaneous hypoxaemia have been observed in fetal sheep. These are usually characterized by a rise in arterial pressure of up to 50 per cent accompanied by a rapid fall in heart rate by about 50 per cent which may last several minutes. They are associated with compression of the umbilical cord (by entanglement with limbs or vascular catheters) or with uterine activity (Jones and Ritchie, 1976; Patrick et al, 1976). During the bradycardia there is a decrease of $\mathrm{PaO}_{2}$ accompanied by an increase in $\mathrm{PaCO}_{2}$ and a fall in $\mathrm{pH}$. These episodes may occur two or three times per hour and can result in abrupt fetal death (fig 3). The metabolic and endocrine changes occurring during these episodes are described below.

\section{ENDOCRINE CHANGES}

During fetal hypoxaemia the plasma concentrations of growth hormone, luteinizing hormone, prolactin and oxytocin show no consistent changes (Alexander, et al, 1973b; C. McMillen, unpublished observations). In contrast plasma ADH concentrations increase substantially during hypoxaemia (Alexander et al, 1973b; Rurak, 1976a and b) and are associated with an inhibition of diuresis and an increase in urine osmolarity (D. Walker, unpublished observations). Bilateral cervical vagotomy can block the rise in plasma ADH concentration (Jones and Rurak, 1976b) but this effect is not always seen (Rurak, 1976a and b).
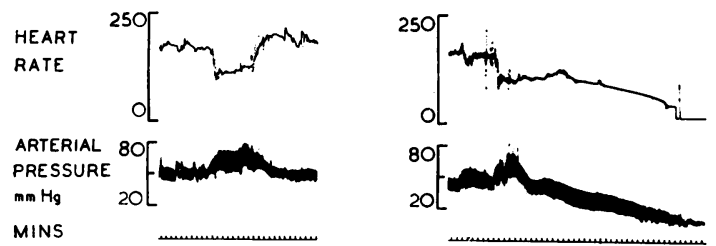

Fig 3 Two episodes of bradycardia and elevated arterial pressure in a fetal sheep at 139 and 140 days. The final episode resulting in abrupt fetal death illustrates the initial rise then gradual fall in arterial pressure observed with acute asphyxia.
The concentration of adrenocorticotrophin (ACTH) in the fetal circulation increases considerably in response to hypoxaemia (Alexander et al, 1973b; Boddy et al, 1974b; Jones et al, 1977) which is unlikely to be the result of activation of the aortic body chemoreceptor as it is not influenced by vagotomy. It is apparent that the hypoxic stimulus does not act at the hypothalamic or pituitary level since mid-brain section blocks the ACTH rise during hypoxaemia (Robinson, Rees, Kendall and Thorburn, unpublished observations). The physiological significance of the rises of ACTH during hypoxaemia is not clear since the corticosteroid output of the fetal sheep adrenal is relatively unresponsive to ACTH until five to 10 days before birth (Bassett and Thorburn, 1973; Madill and Bassett, 1973; Jones et al, 1977). Indeed it is only late in gestation that there is a large corticosteroid response to hypoxaemia (fig 4). Daily periods of hypoxaemia for $60 \mathrm{~min}$, which consistently elevate the concentration of ACTH in fetal plasma, induce the maturation of the corticosteroid response of the fetal adrenal (Jones et al, 1977).

In contrast, the adrenal medullary hormones, adrenaline and noradrenaline, exhibit increases in both adrenal output and plasma concentration (fig 4) in response to hypoxaemia (Comline and Silver, 1961; Jones and Robinson, 1975). During the last 20-30 days of intrauterine life there are no changes in the response to moderate hypoxaemia although there is a large increase in the adrenal response to asphyxia and severe hypoxia. The source of the circulating catecholamines is not entirely clear. Some (particularly dopamine) may originate from paraganglia that are also responsive to hypoxia (Brundin, 1966).

The plasma concentration of pancreatic glucagon increases up to tenfold during hypoxaemia (J. R. Girard and H. J. Shelley, personal communication) while plasma insulin does not change or falls despite a rise in plasma glucose (figs 4 and 5). The plasma insulin concentration, at least, may be under 


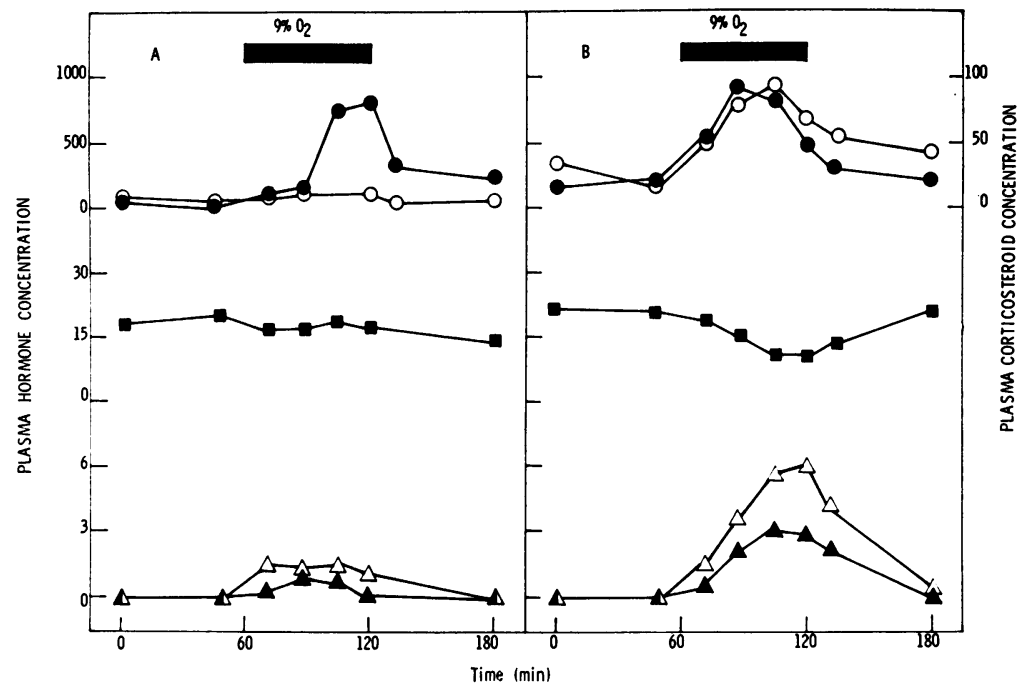

Fig 4 The changes in the concentration of hormones in the plasma of fetal sheep during hypoxaemia. A 118-125 $\frac{\overline{5}}{\mathrm{D}}$ days, B 140-146 days. (०), ACTH $(\mathrm{pg} / \mathrm{ml})$; (O), corticosteroid $(\mathrm{ng} / \mathrm{ml}) ;(\square)$, insulin ( $\mu$ Units $/ m l) ;(\boldsymbol{\Delta})$, adrenaline $\overrightarrow{-}$ (ng/ml); $(\triangle)$, noradrenaline $(\mathrm{ng} / \mathrm{ml})(\square)$ hypoxaemia was induced by causing pregnant sheep to breathe 9 per cent $\mathrm{O}_{2}+3$ per cent $\mathrm{CO}_{2}$ in $\mathrm{N}_{2}$.

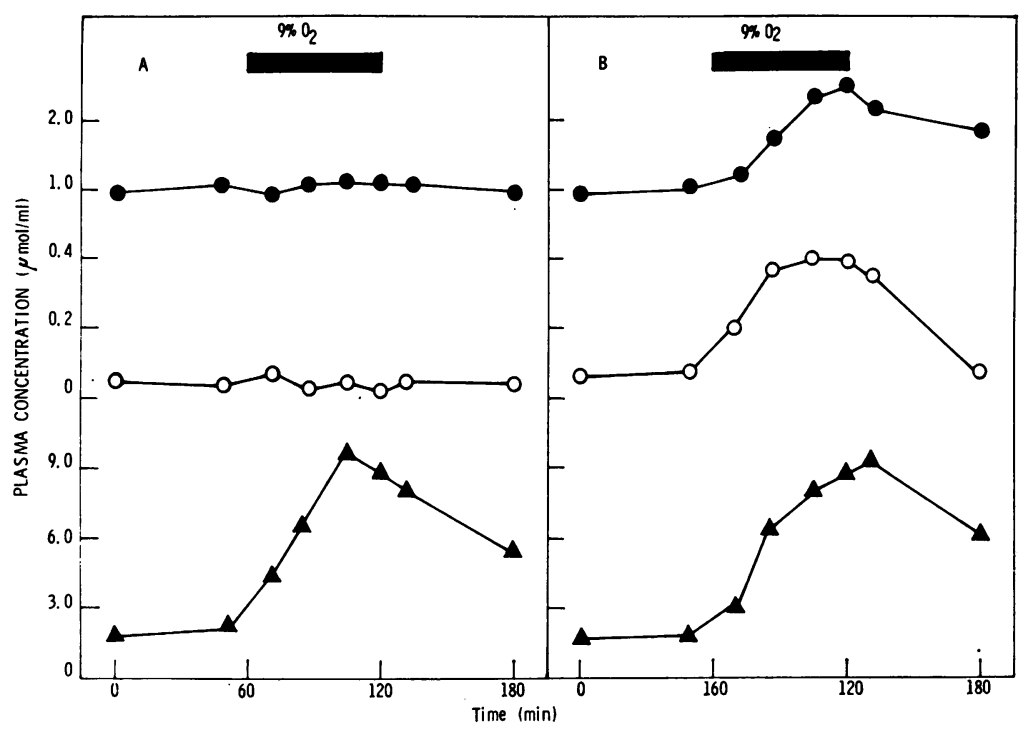

Fig 5 The changes in the concentration of plasma metabolites during hypoxaem in fetal sheep, A $118-122$ days, B 140-146 days. (O), glucose; (C), free fatty acid; ( $\mathbf{\Delta})$,

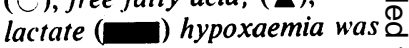
induced by causing pregnant sheep to breathe 9 per cent $\mathrm{O}_{2}+3$ per cent $\mathrm{CO}_{2}$ in $\mathrm{N}_{2}$.

adrenergic control (particularly that of circulating catecholamines) since $\alpha$-adrenergic blockade with phentolamine during hypoxaemia is associated with an increase in fetal plasma insulin concentration.

The changes in plasma ACTH and cortisol concentrations observed during a 60 -min period of experimental hypoxaemia have also been seen during short periods of spontaneous hypoxaemia in utero (Jones and Ritchie, 1976).

METABOLIC RESPONSES

During the course of fetal development tissue glycogen stores change dramatically (Dawes and Shelley, 1968). The concentration in the liver and muscle increases in the last third of gestation. In contrast, the glycogen concentration in the heart and lung is initially high and then decreases. Thus is might be expected that the plasma lactate and glucose responses of the fetal sheep to hypoxi change with gestational age (Alexander et al, 1972 Shelley, 1973; Jones, 1977). Of the organs mentw tioned above, only the liver is capable of mobilizingglycogen to glucose (Scrutton and Utter, 1968) and the increase in hepatic glycogen in the fetal sheep if associated with a rise of plasma glucose in response? to hypoxaemia (Jones, 1977). Before 120 dayso hypoxaemia causes little change in plasma glucos $\overline{\mathrm{C}}^{-}$ concentration while between 120 days and term thd 
response becomes progressively larger (fig 5). It is likely that some of the glucose increase is the result of glycogen mobilization and similar rises in response to adrenaline or isoprenaline infusion support this view as does stimulation of glycogenolysis in the perfused fetal liver by adrenaline (Bassett and Jones, 1976). The absence of a change or a fall in plasma insulin concentration is clearly also important since the $\alpha$-blocker, phentolamine, which prevents adrenergic inhibition of insulin secretion (Woods and Porte, 1974), blocked the hypoxia-induced rise in glucose (Bassett and Jones, 1976).

Normally hypoxaemia causes four to eight-fold increases in plasma lactate concentration (fig 5) and the high lactate concentration persists for several hours after hypoxia (Britton et al, 1967b; Alexander et al, 1972; Shelley, 1973; Jones, 1977). Despite the large changes in tissue glycogen concentration, these responses did not change significantly over the latter third of pregnancy (Jones, 1977). Apart from the large glycogen stores, which are depleted during hypoxaemia (Shelley, 1973), the relative impermeability of the sheep placenta to lactate (Britton et al, $1967 \mathrm{a})$ and the probable inability of the fetal tissue to increase their lactate consumption (Jones, 1977) contribute to the persistent high plasma lactate concentration. The placenta is also an important source of lactate (Burd et al, 1975; Jones and Rurak, 1976a) and placental lactate output increases during hypoxia (C. T. Jones and D. Walker, unpublished observations).

The fetal sheep has little stored fat (Body and Shorland, 1964; Body et al, 1966) and this is reflected in the very low plasma concentration of free fatty acid (Van Duyne et al, 1960). There is, however, a rise in the plasma concentration during the latter third of pregnancy but even close to term it is still a tenth of the maternal concentration (Jones, 1977). During hypoxaemia there is little change in the plasma concentration of free fatty acid in the fetus until after 130 days and substantial increases are not seen until several days before birth (fig 5). The increase in free fatty acid concentrations in plasma during hypoxaemia correlate with the rise in plasma catecholamines (Jones, 1977) and may be related to the development of the response of the adrenal medulla to hypoxaemia (Comline and Silver, 1961). Plasma ketone body concentrations parallel those of the free fatty acids both at rest and during hypoxaemia (Jones, 1977). Since the liver of the fetal sheep metabolizes fatty acids to ketone bodies several days before birth (Alexander et al, 1973a), a close correlation between the two is not surprising.

The metabolite changes seen during experimental hypoxaemia have been observed during short periods of spontaneous hypoxaemia (Jones and Ritchie, 1976).
Long-term or chronic hypoxaemia

\section{CARDIOVASCULAR CHANGES}

Chronic hypoxaemia in fetal sheep has been produced experimentally by interference with the placental vasculature. Emmanouilides et al (1968) ligated one umbilical artery and demonstrated hypoxaemia in association with reduced fetal weight at delivery but did not report any cardiovascular changes.

The sheep uterus contains folds of endometrium called caruncles, some of which form the maternal cotyledons in pregnancy. Removal of caruncles results in a reduction of placental size in a subsequent pregnancy, and Alexander (1964) demonstrated that this is associated with an increased incidence of intrauterine deaths, premature delivery and reduced birthweight. Using this technique Robinson et al (1976) observed fetal growth retardation in three of six pregnancies. The growth-retarded fetuses were chronically hypoxaemic $\left(\mathrm{PaO}_{2}\right.$ down by 37 per cent) while the normal-sized fetuses were hypoxaemic late in gestation. Recordings of fetal heart rate and arterial pressure have been made in five fetuses (three small and two normal sized). In all fetuses the resting heart rate and blood pressure were similar to controls. However, in two small and one ncrmal-sized fetus spontaneous periods of bradycardia (fig 6) similar to those described earlier but with no simple physical explanation were observed.

Long-term reduction of fetal $\mathrm{PaO}_{2}$ (down by 15 per cent) with raised haematocrit and no acidaemia has been produced by embolization of the maternal side of the placenta by daily injections of $15 \mu$ microspheres into the uterine circulation (Creasy et al, 1972, 1973). Embolization resulted in significantly reduced placental and fetal weight with changes in organ weights similar to that described in the growth-retarded human fetus (Gruenwald, 1963;

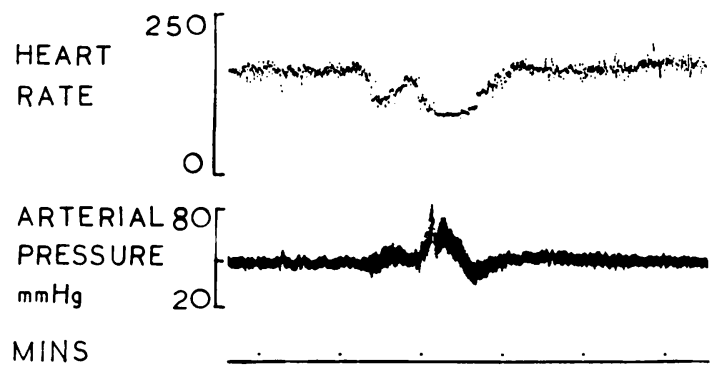

Fig 6 Spontaneous fetal bradycardia and increased arterial pressure in a normal-sized fetus. These episodes occurred with gradually increasing frequency from 137 days until delivery. Before pregnancy the number of placental attachment sites was reduced by removal of endometrial caruncles. 
Naeye, 1965). At about 139 days fetal cardiac output and its distribution were measured using radioactively labelled microspheres and compared with controls. Fetal cardiac output was reduced by approximately one third in the embolized group. The proportion of cardiac output distributed to the brain, heart, kidney and gut was increased while that to the placenta and lung was reduced (table II).

\begin{tabular}{lcc}
\hline & Control & Embolized \\
\hline Cardiac output $\left(\mathrm{ml} \mathrm{min}^{-1}\right)$ & 1807 & $1171^{*}$ \\
Percentage cardiac output to & & \\
Brain & $3 \cdot 4$ & $6 \cdot 8^{*}$ \\
Heart & $2 \cdot 3$ & $4 \cdot 5^{*}$ \\
Gut & $6 \cdot 6$ & $10 \cdot 8^{*}$ \\
Kidney & $3 \cdot 1$ & $5 \cdot 0^{*}$ \\
Lung & $5 \cdot 4$ & $1 \cdot 7^{*}$ \\
Placenta & $41 \cdot 9$ & $29 \cdot 1^{*}$ \\
\hline
\end{tabular}

Table II Distribution of fetal cardiac output with embolization of the uterine circulation (Creasy et al, 1973)

${ }^{*} \mathrm{P}<0.05$.

\section{ENDOCRINE CHANGES}

Relatively little information exists on the effects of long-term hypoxaemia on hormone concentrations in the fetus. During hypoxaemia induced by a surgical reduction of placental mass fetal plasma ACTH concentration remains low for most of the period of observation and plasma insulin is about half its normal concentration.

\section{METABOLIC RESPONSES}

Hypoxaemia for longer than 60 min causes a fall in hepatic glycogen (Shelley, 1973) in association with maintenance of a high fetal plasma glucose. Clearly this cannot persist and in long-term hypoxaemia there is a low plasma glucose and high plasma lactate (Shelley, 1973). In chronic hypoxaemia caused by a reduction of placental mass a persistently low plasma glucose concentration is also seen but with a low plasma lactate concentration. Thus a low fetal blood glucose concentration is likely to be a feature of chronic hypoxaemia while the plasma lactate concentration will possibly be dependent on the origin of the hypoxaemia.

\section{Conclusion}

The changes occurring in the fetus during short-term hypoxaemia are probably essential for the function of vital organs at the expense of others. The redistribution of cardiac output increases flow to the brain and heart while reducing that to other tissues such as muscles and lungs. At the same time there is mobilization of hepatic glycogen and a reduction of glucose uptake by the insulin-sensitive tissues improving the supply of glucose to the brain. This is an importagt factor in survival during asphyxia (Dawes et al, 1963; Mann, 1970).

Accounting for the changes observed during chronic hypoxaemia is more difficult. Redistributiof of cardiac output similar to that seen with shor term hypoxaemia occurs. The reduced flow to some organs may be partly responsible for their reduceg growth. But the low plasma glucose accompanied by the low insulin concentration is probably one of the major factors accounting for the reduced growtit rate. On the other hand, compensatory mechanisnd such as increased erythropoiesis results in increas packed cell volume and thus almost normal oxygeh content may protect the fetus from hypoxaemia.

This work was supported by grants from the M.R. $\dot{\dot{C}}$ and The Wellcome Trust. GDT is a member of the external staff of the M.R.C.

\section{References}

Alexander, D. P., Andrews, W. H. H., Britton, H. G., an Nixon, D. A. (1973a). Hepatic ketone body metabolism in the foetal and neonatal sheep. Journal of Physiology, 230. 22P-23P.

Alexander, D. P., Britton, H. G., Forsling, M. L., Nifo메त D. A., and Ratcliffe, J. G. (1973b). Adrenocorticotrophin and vasopressin in foetal sheep and the response to stress In The Endocrinology of Pregnancy and Parturition: Exper mental Studies in the Sheep, edited by C. G. Pierrepoin? pp. 112-125. Alpha Omega Alpha, Cardiff.

Alexander, D. P., Forsling, M. L., Martin, M. J., Nixop? D. A., Ratcliffe, J. G., Redstone, D., and Tunbridge, Do (1972). The effect of maternal hypoxia on fetal pituitar hormone release in the sheep. Biology of the Neonate, $2 \frac{1}{3}$ 219-228.

Alexander, G. (1964). Studies on the placenta of the sheept (Ovis aries L.). Effect of surgical reduction in the number of? caruncles. Journal of Reproduction and Fertility, 7, 307-325 Bassett, J. M., and Jones, C. T. (1976). Foetal glucose metao bolism. In Fetal Physiology and Medicine, edited by R. Wó Beard and P. W. Nathanielsz, pp. 158-172. Saunders London.

Bassett, J. M., and Thorburn, G. D. (1973). Circulating leve? of progesterone and corticosteroids in the pregnant ewe and its foetus. In The Endocrinology of Pregnancy and Parture tion: Experimental Studies in the Sheep, edited by C. $G_{D}$ Pierrepoint, pp. 126-140. Alpha Omega Alpha, Cardiff.

Boddy, K., Dawes, G. S., Fisher, R., Pinter, S., and Robinson, J. S. (1974a). Foetal respiratory movements, electrod cortical and cardiovascular responses to hypoxaemia ane hypercapnia in sheep. Journal of Physiology, 243, 599-618

Boddy, K., Jones, C. T., Mantell, C., Ratcliffe, J. G., and Robinson, J. S. (1974b). Changes in plasma ACTH an\& corticosteroid of the maternal and fetal sheep durin hypoxia. Endocrinology, 94, 588-591.

Body, D. R., and Shorland, F. B. (1964). Maternal and foet lipids of sheep. Nature, 202, 769.

Body, D. R., Shorland, F. B., and Gass, J. P. (1966). The foetal and maternal lipids of Romney sheep. I. The compo sition of the lipids of the total tissues. Biochimica Bio physica Acta, 125, 207-216. 
Britton, H. G., Hugget, A. St. G., and Nixon, D. A. (1967a). Carbohydrate metabolism in the sheep placenta. Biochimica Biophysica Acta, 136, 426-440.

Britton, H. G., Nixon, D. A., and Wright, G. H. (1967b). The effects of acute hypoxia on the sheep foetus and some observations on recovery from hypoxia. Biologia Neonatorum, 11, 277-301.

Brundin, T. (1966). Studies on preaortal paraganglia of newborn rabbits. Acta Physiologica Scandinavica, Suppl. 290 $1-54$.

Burd, L. I., Jones, M. D., Jr., Simmons, M. A., Makowski, E. L., Meschia, G., and Battaglia, F. C. (1975). Placental production and foetal utilisation of lactate and pyruvate. Nature, 254, 710-711.

Cohn, H. E., Sacks, E. J., Heymann, M. A., and Rudolph, A. M. (1974). Cardiovascular responses to hypoxemia and acidemia in fetal lambs. American Journal of Obstetrics and Gynecology, 120, 817-824.

Comline, R. S., and Silver, M. (1961). The release of adrenaline and noradrenaline from the adrenal glands of the foetal sheep. Journal of Physiology, 156, 424-444.

Creasy, R. K., Barrett, C. T., de Swiet, M., Kahanpää, K. V., and Rudolph, A. M. (1972). Experimental intrauterine growth retardation in the sheep. American Journal of Obstetrics and Gynecology, 112, 566-573.

Creasy, R. K., de Swiet, M., Kahanpää, K. V., Young, W. P., and Rudolph, A. M. (1973). Pathophysiological changes in the foetal lamb with growth retardation. In Foetal and Neonatal Physiology (Sir Joseph Barcroft Centenary Symposium, 1972), edited by R. S. Comline, K. W. Cross, G. S. Dawes, and P. W. Nathanielsz, pp. 398-402. Cambridge University Press, London.

Dawes, G. S. (1968). Foetal and Neonatal Physiology, p. 97. Year Book Medical Publishers, Chicago.

Dawes, G. S., Duncan, S. L. B., Lewis, B. V., Merlet, C. L., Owen-Thomas, J. B., and Reeves, J. T. (1969). Hypoxaemia and aortic chemoreceptor function in foetal lambs. Journal of Physiology, 201, 105-116.

Dawes, G. S., Jacobson, H. N., Mott, J. C., Shelley, H. J., and Stafford, A. (1963). The treatment of asphyxiated, mature foetal lambs and rhesus monkeys with intravenous glucose and sodium carbonate. Journal of Physiology, 169, 167-184.

Dawes, G. S., and Shelley, H. J. (1968). Physiological aspects of carbohydrate metabolism in the foetus and newborn. In Carbohydrate Metabolism and its Disorders, edited by $\mathrm{F}$. Dickens, P. J. Randle, and W. J. Whelan, Vol. 2, pp. 87-121. Academic Press, London and New York.

Emmanouilides, G. C., Townsend, D. E., and Bauer, R. A. (1968). Effects of single umbilical artery ligation in the lamb fetus. Pediatrics, 42, 919-927.

Friedman, W. F. (1972). The intrinsic physiologic properties of the developing heart. Progress in Cardiovascular Disease, 15, 87-111.

Friedman, W. F., Pool, P. E., Jacobowitz, D., Seagren, S. C., and Braunwald, E. (1968). Sympathetic innervation of the developing rabbit heart: biochemical and histochemical comparison of fetal, neonatal, and adult myocardium. Circulation Research, 23, 25-32.

Gruenwald, P. (1963). Chronic fetal distress and placental insufficiency. Biologia Neonatorum, 5, 215-265.

Jones, C. T. (1977). The development of some metabolic responses to hypoxia in the foetal sheep. Journal of Physio$\log y, 266,743-762$.

Jones, C. T., Boddy, K., Robinson, J. S., and Ratcliffe, J. G. (1977). Developmental changes in the responses of the adrenal glands of foetal sheep to endogenous adreno- corticotrophin as indicated by the hormone responses to hypoxaemia. Journal of Endocrinology, 72, 279-292.

Jones, C. T., and Ritchie, J. W. K. (1976). Endocrine and metabolic changes associated with periods of spontaneous hypoxia in fetal sheep. Biology of the Neonate, 29, 286-293.

Jones, C. T., Ritchie, J. W. K., and Flint, A. P. F. (1977). Some experiments on the role of the foetal pituitary in the maturation of the foetal adrenal and the induction of parturition in sheep. Journal of Endocrinology, 72, 251-257.

Jones, C. T., and Robinson, R. O. (1975). Plasma catecholamines in foetal and adult sheep. Journal of Physiology, 248, 15-33.

Jones, C. T., and Rurak, D. (1976a). The distribution and clearance of hormones and metabolites in the circulation of the foetal sheep. Quarterly Journal of Experimental Physio$\log y, 61,287-295$.

Jones, C. T., and Rurak, D. (1976b). Absence of a correlation between the secretion of adrenocorticotrophin and vasopressin in foetal sheep. Journal of Endocrinology, 70, 327 328.

Madill, D., and Bassett, J. M. (1973). Cortocosteroid release by adrenal tissue from foetal and newborn lambs in response to corticotrophin stimulation in a perifusion system in vitro. Journal of Endocrinology, 58, 75-87.

Mann, L. I. (1970). Effects of hypoxia on umbilical circulation and fetal metabolism. American Journal of Physiology, 218, 1453-1458.

Naeye, R. L. (1965). Malnutrition. Probable cause of fetal growth retardation. Archives of Pathology, 79, 284-291.

Patrick, J. E., Dalton, K. J., and Dawes, G. S. (1976). Breathing patterns before death in fetal lambs. American Journal of Obstetrics and Gynecology, 125, 73-78.

Ritchie, J. W. K. (1975). The endocrine, metabolic and cardiovascular effects of catecholamines in the sheep fetus. MD Thesis, Queen's University, Belfast.

Robinson, J. S., Jones, C. T., Challis, J. R. G., and Thorburn, G. D. (1976). Observations on experimental intrauterine growth retardation in sheep. (Abstract). Pediatric $\boldsymbol{R e}$ search, 10, 891.

Rurak, D. W. (1976a). Some aspects of the physiology of arginine-vasopressin in fetal sheep. DPhil Thesis, Oxford University.

Rurak, D. W. (1976b). Plasma vasopressin in foetal lambs. Journal of Physiology, 256, 36P-37P.

Scrutton, M. C., and Utter, M. F. (1968). The regulation of glycolysis and gluconeogenesis in animal tissues. Annual Review of Biochemistry, 37, 249-302.

Shelley, H. J. (1973). The use of chronically catheterized foetal lambs for the study of foetal metabolism. In Foetal and Neonatal Physiology (Sir Joseph Barcroft Centenary Symposium, 1972), edited by R. S. Comline, K. W. Cross, G. S. Dawes, and P. W. Nathanielsz, pp. 360-381. Cambridge University Press, London.

Shinebourne, E. A., Vapaavuori, E. K., Williams, R. L., Heymann, M. A., and Rudolph, A. M. (1972). Development of baroreflex activity in unanesthetized fetal and neonatal lambs. Circulation Research, 31, 710-718.

Towell, M. E., and Salvador, H. S. (1974). Intrauterine asphyxia and respiratory movements in the fetal goat. American Journal of Obstetrics and Gynecology, 118, 1124 1131.

Van Duyne, C. M., Parker, H. R., Havel, R. J., and Holm, L. W. (1960). Free fatty acid metabolism in fetal and newborn sheep. American Journal of Physiology, 199, 987-990.

Woods, S. C., and Porte, D., Jr. (1974). Neural control of the endocrine pancreas. Physiol. Reviews, 54, 596-619. 